\title{
Local autonomic failure affecting a limb
}

\author{
R H JOHNSON, B J ROBINSON \\ From the Wellington School of Medicine, Wellington, New Zealand
}

SUMMARY Three patients are described who presented with autonomic failure affecting predominantly one limb. Physiological studies revealed that there was sweating loss in the limb which appeared to be due to a preganglionic autonomic lesion and not to a sweat gland abnormality. In all three patients there was also evidence of failure of vasomotor control. There was no evidence of more generalised autonomic failure or neurological deficit. In two patients the condition appeared to be static and, according to the patients' accounts was life long. In the third the sweating loss was present for three years prior to pain loss becoming evident from $\mathrm{C} 2 / 3$ to $\mathrm{T} 1$ on the same side as the sweating loss. These patients, together with two recent case reports, indicate that isolated local autonomic failure, probably from a discrete cord lesion, can be a cause of presenting symptoms related to sweating loss or to change in temperature in a limb.

Localised anhidrosis usually occurs in association with a generalised disease such as diabetes mellitus or multiple system atrophy, or a local disorder affecting autonomic nerves such as a peripheral nerve lesion. ${ }^{1}$ Patients have also been described with localised anhidrosis which is not apparently related to other neurological deficits. Faden and his colleagues in 1982 described a 22 year old man in whom there was segmental anhidrosis which progressed over the next two years. ${ }^{2}$ A further report has described eight similar adult patients. ${ }^{3}$ In neither of these reports are tests of vasomotor function described and the abnormality was thought to affect sweating alone. We have investigated three patients with a similar disorder and in all our subjects we have found evidence that the autonomic failure also involves vasomotor function.

\section{Case reports}

\section{Patient 1}

A European female, a housewife, aged 56 years, complained of numbness of the fingers of the left hand. She had also noticed reduction in sweating in the hand which particularly prevented her gripping her tennis racquet effectively. These symptoms had probably been life-long and definitely present for at least 10 years. On examination the left hand was dry and colder than the right hand. There was no evidence of orthostatic hypotension and heart rate was normal and increased on standing. There was no Horner's syndrome.

Address for reprint requests: Prof RH Johnson, Wellington School of Medicine, Private Bag, Wellington Hospital, Wellington, New Zealand.

Received 3 June 1986. Accepted 25 June 1986
There was no weakness or wasting of the hand or arm and no demonstrable sensory deficit. Pulses and blood pressure were equal in the two limbs. The patient was followed up for 6 years with no change being observed. Blood screening test including vitamin $\mathbf{B}_{12}$ were normal, a cervical spine radioe graph showed moderately advanced degenerative changes of $\vec{P}$ the spine. Radiographs of the thoracic outlet did not revead a cervical rib. A carpal tunnel syndrome was considered an: the median nerve conduction time was at the lower level of. normal.

\section{Patient 2}

A European male, a labourer, aged 21 years, first noticed at the age of 15 years after running a cross country race that the right side of the face, upper chest and right arm were red whereas the left side was white. He also noticed that he had reduced sweating on the left side of his face and over his left arm. The condition had not been progressive nor did it cause him any disability. There was no past history of trauma to the neck, shoulder or arm. On examination he appeared fit and healthy. The left hand felt dry and there was less hair over the left forearm and the left upper chest. There was no orthostatic hypotension, heart rate was normal and increased on standing. There was no Horner's syndrome. There was no weakness, wasting of the hand or arm and no sensory deficit. Pulses and blood pressure were equal in the two limbs. Forearm circumference showed a difference, the left forearm being about $2 \mathrm{~cm}$ less than on the right, $10 \mathrm{~cm}$ below the olecranon process. The patient was right handed. Blood screen tests were normal. Radiographs of the spine and thoracic outlet were normal. The patient was followed up for 10 years and remained well. After 9 years however he complained of weakness in his right leg over a few days which was subjective only. Blood tests including WR and ESR (1 mm/hour) were normal. Radiographs of his cervical, dorsal and lumbar spines and a myelogram, which included 

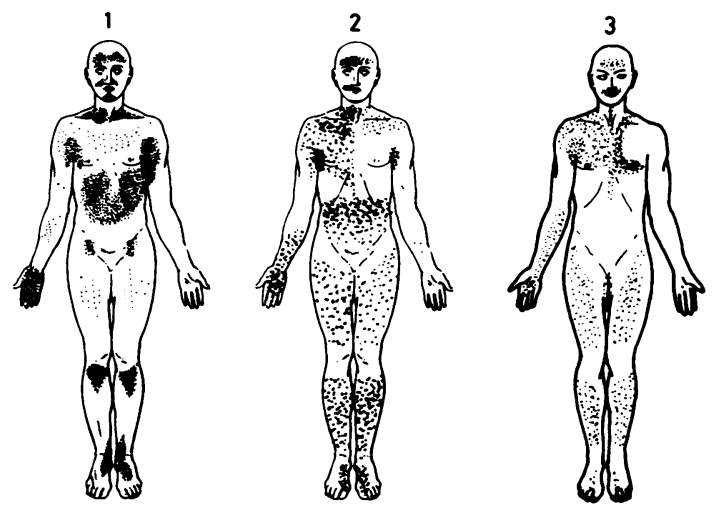

Fig 1 Sweating distribution using quinizarin test. Patient 1 after 33 minutes heating (oral temperature $37 \cdot 4^{\circ} \mathrm{C}$ ); Patient 2 after 25 minutes heating (oral temperature $37 \cdot 0^{\circ} \mathrm{C}$ ); Patient 3 after 36 minutes heating (oral temperature $37 \cdot 5^{\circ} \mathrm{C}$ ). the cervical region, were normal. Cerebrospinal fluid checks including Lange curve were also normal.

\section{Patient 3}

A European male, a carpenter, aged 46 years, presented with a 9 month history of coldness in his left hand and arm. The hand was occasionally slightly bluer than the right hand. The hand was sometimes the same temperature as the other side and sometimes tingled when cold. Apart from feeling that he could not use the arm as easily and that he dropped small items such as screws and fumbled when picking them up, he did not have any weakness or other problem with the arm. He said that on the occasions when he drank alcohol, his left arm felt as if it was "on fire". He had a past history of gout and a congenital talepes affecting his right leg and wore a built-up shoe on that side. On examination the most obvious feature was that the left hand was dry and darker in colour compared with the right hand, which was sweating. There was no orthostatic hypotension and studies of heart rate for vagal function revealed no abnormality (Valsalva's test, 13:15 ratio on standing, deep breathing). ${ }^{4}$ There was no wasting or loss of power. Reflexes were easily obtainable equal and not exaggerated. There was no sensory loss. On

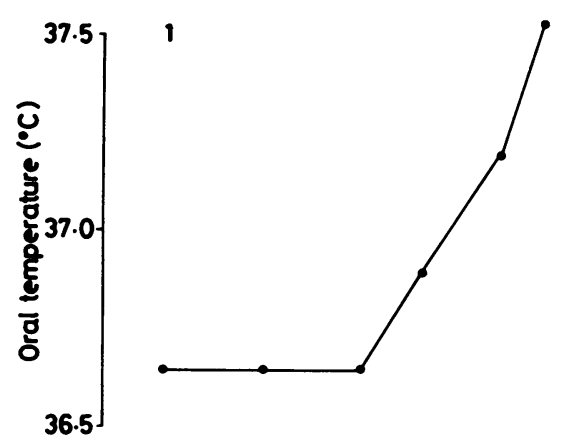

Radiant heat

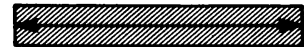

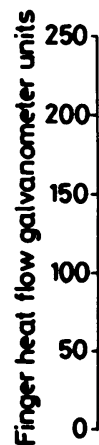

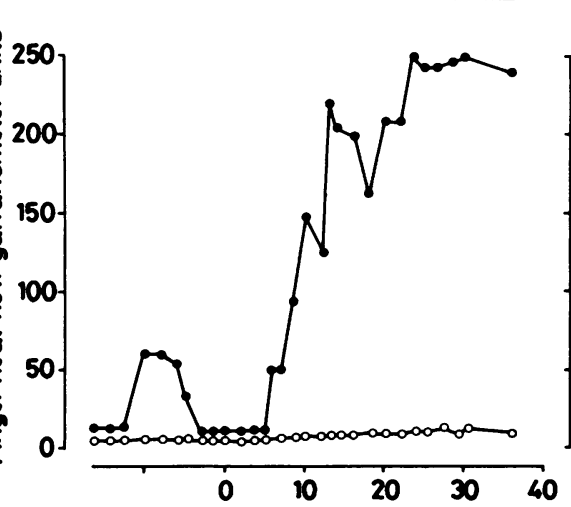

2

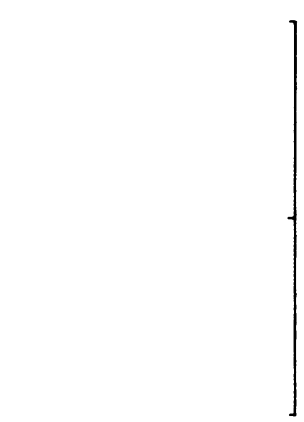

Radiant heat "บIIIIIIIIII

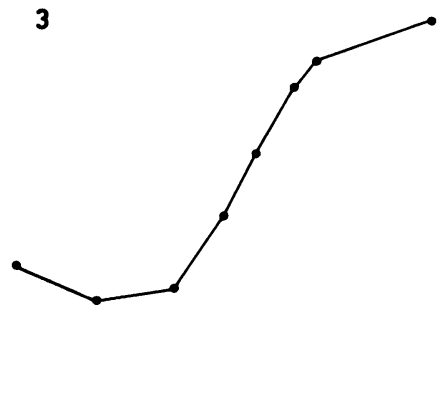

Radiant heat

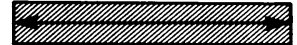

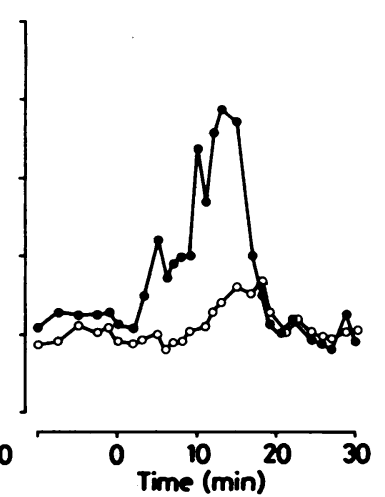

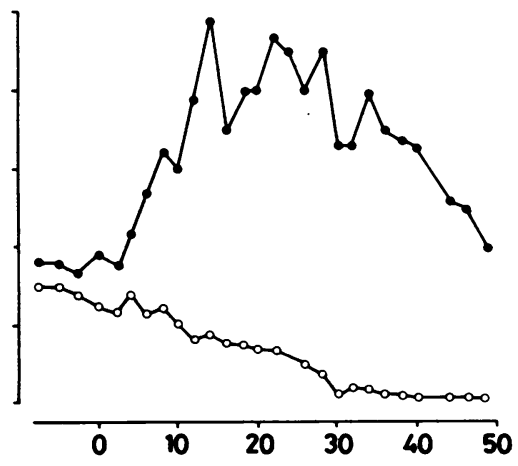

Fig 2 The responses of oral temperature $\left({ }^{\circ} \mathrm{C}, 2\right.$ patients only) and finger blood flow (galvanometer units) in the 3 patients in response to radiant heating of the trunk for the periods shown by the horizontal bars. Responses from the right (unaffected) hands are shown by the closed circles, responses for the left (affected) hands are shown by the open circles. 

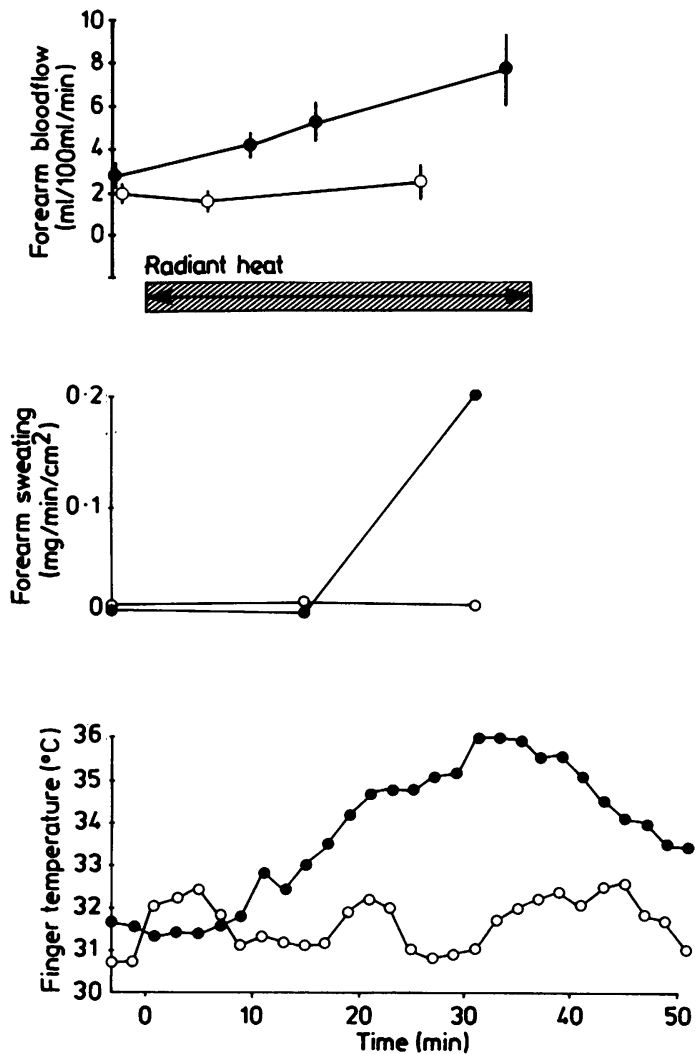

Fig 3 Forearm blood flow, forearm sweating and finger temperature in Patient 3 during radiant heating of the trunk for the period shown by the horizontal bar. Responses in the right (unaffected) arm are shown by the closed circles, responses from the left (affected) arm are shown by the open circles.

immersing the hands in warm water (about $40^{\circ} \mathrm{C}$ ) the skin of the left hand did not wrinkle whereas that of the right hand did so. ${ }^{5}$ The clinical complaints remained virtually the same during follow-up for 3 years: there was no weakness in the hand or arm. However, there was then a complaint of dullness of sensation over the left shoulder but it was not possible to define it clinically with accuracy. It appeared to extend from $\mathrm{C} 2$ to $\mathrm{T} 1$ spinal levels and involved pinprick sensation only. Blood screening tests were normal (haemoglobin, red cells, white cells, platelets, ESR ( $21 \mathrm{~mm}$ in $1 \mathrm{~h})$, glucose, creatinine, urea, VDRL non-reactive, electrolytes normal, proteins normal, rheumatoid factor negative and thyroid function tests normal). Radiographs of the chest, cervical spine and thoracic outlet were normal. An arch angiogram including left axillary arteriogram showed no arterial lesion though slow flow in the left axillary artery was noted, probably related to the coldness of the limb at the time. The following investigations were carried out 3 years after presentation. CT scans of the neck, brain and brain stem were normal. Myelography and studies of CSF were also normal (total protein: 0.36 g/l, IgG: $0.029 \mathrm{~g} / 1$, glucose:
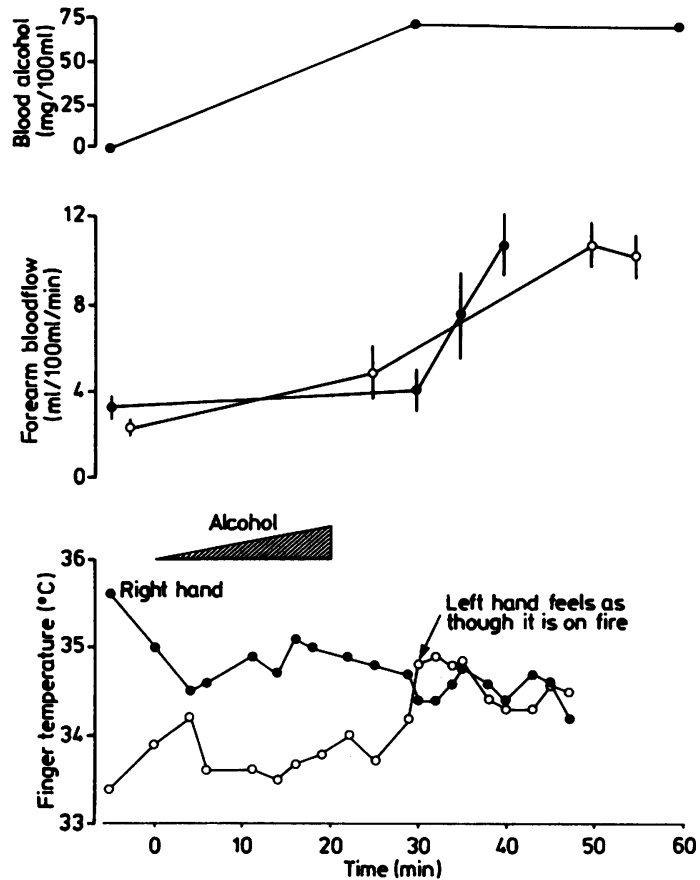

Fig 4 Patient 3, finger skin temperature, forearm blood flow and blood alcohol responses to ingestion of $45 \mathrm{~g}$ of alcohol.

$3.6 \mathrm{mmol} / \mathrm{l})$. The ECG was normal and an EMG showed normal ulnar motor and sensory conduction and radial sensory conduction but a minor reduction of the left median nerve distal velocity (not temperature related) compatible with a left carpal tunnel syndrome.

\section{Autonomic investigations}

Sweating distribution was observed in each patient by applying quinizarin powder to the skin. ${ }^{6}$ The patients were heated by a radiant heat cradle (six $60 \mathrm{~W}$ lamps). In all patients there was sweating loss over the affected arm and this extended over the chest in two of the three patients (fig 1). Skin biopsies were taken in patients 1 and 2 and revealed normal numbers of sweat glands. Those in patient 2 were somewhat atrophic on the affected side.

Blood flows were studied in each patient using Hatfield-Turner copper tellurium heat flow discs on the fingers. ${ }^{7}$ Forearm blood flow was also measured in patient 3 only using venous occlusion plethysmography with an electrically calibrated mercury-in-rubber strain gauge plethysmograph. ${ }^{8}$ Observations were made during radiant heating of the trunk by a radiant heat cradle. Oral temperatures were measured using a thermocouple thermometer (Ellab). In all patients vasodilatation occurred promptly on the normal side but was absent on the affected side (figs 2,3).

In patient 3 , who complained that his arm felt that it was on fire when he drank alcohol, forearm blood flow was examined with a mercury-in-rubber strain gauge plethysmograph and skin temperature was also measured on the forefinger of each hand while the patient drank alcohol 
$(45 \mathrm{~g})$. Blood alcohol increased to $75 \mathrm{mg}$ per $100 \mathrm{ml}$ and blood flow increased in both arms so that finger temperatures were equal (fig 4). While the vasodilatation was present the effect was studied of mental arithmetic and immersing the opposite arm in cold water (cold pressor test). Mental arithmetic caused a reduction in blood flow in the right (normal) arm but no change in the left (abnormal) arm. The cold pressor test caused a reduction in blood flow in both arms. A response to mental arithmetic implies that autonomic pathways throughout the central and peripheral autonomic nervous system were functioning: there would be no response if any level was affected. The response to the cold pressor test was in keeping with the response being dependent upon a spinal reflex only, similar to the gasp reflex. ${ }^{9}$ The normal response to the cold pressor test in patient 3 implied that his lesion lies in the central nervous system in or above the upper part of the cervical cord.

Postganglionic axon reflex activity, which produces local sweating and piloerection, was studied around intradermal injections of $1 \%$ acetylcholine solution ${ }^{110}$ in the affected arm and also the normal arm. In all patients sweating and piloerection occurred around the site of the injections, implying that postganglionic sympathetic nerves were present and functional in each patient in the affected areas. Pupillary responses were investigated in two patients. Topical adrenaline $(0 \cdot 1 \%)$ in patient 2 and hydroxyamphetamine $(1 \%)$ in patient 3 showed no hypersensitivity in the eye on the side of the body affected. This implies no sympathetic dysfunction of the pupils. ${ }^{11}$

\section{Discussion}

All three patients had localised evidence of autonomic failure affecting one arm only. Investigations imply that not only was there sweating loss with anhidrosis or hypohidrosis but also that there was failure of vasomotor control subserving thermoregulation. Peripheral vasodilatation in response to radiant heating of the trunk depends upon fibre pathways that descend through the cervical spinal cord and probably pass through the brain. ${ }^{1213}$ That the lesion was probably in the cervical cord may be implied by the normal responses to intradermal injection of acetylcholine, indicating normal postganglionic sympathetic fibres, and also the normal response to the cold pressor test in patient 3 which was in keeping with functional sympathetic pathways peripherally and at the immediate spinal level. The affected part of the sympathetic pathway must therefore have been in the upper cervical cord or brain stem. Patients 1 and 2 were briefly mentioned in a general textbook on the autonomic nervous system ${ }^{1}$ and this is the first account of them in more detail. The intervening time has allowed follow-up of one patient for 6 years and the other for 10 years although both patients are now lost to follow-up. The third patient has been followed-up for 3 years. The lesions are therefore predominantly autonomic and in two of the three patients have not apparently been progressive although in patient 3 the involvement of some pain fibres now implies a progressive lesion.

There have been few reports of similar patients. One is of a single patient ${ }^{2}$ and the other is of eight patients. ${ }^{3}$ The single case report by Faden and his colleagues was of a patient with progressive segmental anhidrosis. ${ }^{2}$ No observations were made, however, of vasomotor function. Low and his colleagues $^{3}$ also concentrated their observations on the anhidrotic symptoms and there were no studies of vasomotor function reported although they comment on capillary abnormalities in four patients. These consisted of Raynaud's phenomenon in two patients and "vasospastic" symptoms in a further two patients.

In our three patients, the patient reported by Faden $^{2}$ and also four of the patients reported by Low and his colleagues, ${ }^{3}$ evidence has suggested a preganglionic lesion. Such a lesion might be in the cervical cord and syringomyelia would be a possible pathological process. Syringomyelia may take many years to develop and may involve autonomic fibres. However, when autonomic function is affected, most reports refer to Horner's syndrome and there are no previous reports of cases similar to ours in which the autonomic failure was the most obvious problem.

The involvement of sensory pathways in the last of our cases makes syringomyelia a more likely possibility than in the other two patients but radiological studies were negative. Further, in three studies of a total of twelve patients with syringomyelia or syringobulbia in whom dysautonomic features were present $^{14-16}$ no local autonomic failure similar to that in our patients was reported, all patients having failure of blood pressure regulation. In all patients except possibly one (Case 3 of Hampton et al $^{16}$ ) sensory or motor symptoms preceded autonomic dysfunction by up to 36 years.

Segmental anhidrosis has been reported in Adie's syndrome but our patients had no features of this disorder. Differences in sweating between the two sides of the body may also occur with pressure on the skin, ${ }^{17}$ different exposure to heat unilaterally, ${ }^{18}$ or with pressure on peripheral sympathetic nerves as with cervical rib ${ }^{19}$ or osteoma. ${ }^{20}$ There was no evidence for any of these mechanisms in our patients.

In patient 3 we observed marked dilatation in the affected limb following oral alcohol. Fewings and his colleagues $^{21}$ examined vasodilatation in a patient with unilaterial sympathectomy in one arm (brachial plexus avulsion) following a similar oral dose of alcohol. Their patient had a marked increase in hand blood flow only on the unaffected side, the denervated side remaining unchanged. They concluded that skin vasodilatation following alcohol ingestion was due to an alcohol effect on central vasomotor centres rather 
than a peripheral one directly on blood vessels. However, alcohol has been shown to have peripheral effects on vascular smooth muscle possibly by attentuating the responses to vasoactive substances such as catecholamines or prostaglandins. ${ }^{22}$ The patient that Fewings and his colleagues described had a postganglionic lesion unlike our patient, who had a preganglionic lesion. ${ }^{21}$ Our observation suggests that, in man, alcohol induced skin vasodilatation is at least in part due to a peripheral effect which requires intact postganglionic innervation of the blood vessels.

These patients have had symptoms and signs related to autonomic failure affecting vasomotor as well as sudomotor function. Our physiological studies indicated that both functions were affected. We draw attention in particular to the vasomotor paralysis as this has not been noted or studied in the two other reports ${ }^{2}$ of similar patients.

\section{References}

1 Johnson RH, Spalding JMK. Disorders of the autonomic nervous system. Oxford: Blackwell Scientific Publications, 1974.

2 Faden AI, Chan P, Mendoza E. Progressive isolated segmental anhidrosis. Arch Neurol 1982;39:172-5.

3 Low PA, Fealey RD, Sheps SG, Su WPD, Trautmann JC, Kuntz NL. Chronic idiopathic anhidrosis. Ann Neurol 1985;18:344-8.

4 Johnson RH, Lambie DG, Spalding JMK. Neurocardiology: The inter-relationships between dysfunction in the nervous and cardiovascular systems. London: WB Saunders Co, 1984.

5 O'Riain S. New and simple test of nerve function in hand. Br Med J 1973;3:615-6.

6 Guttmann L. Topographic studies of disturbances of sweat secretion after complete lesions of peripheral nerves. J Neurol Psychiatry 1940;3:197-210.

7 Hatfield HS. A heat flow meter. J Physiol (Lond) 1950;111:10P.

8 Hokanson DE, Sumner DS, Strandness DE. An electrically calibrated plethysmograph for direct measure- ment of limb blood flow. IEEE Trans Biomed Eng 1975;22:25-9.

9 Gilliatt RW, Guttmann L, Whitteridge D. Inspiratory vaso-constriction in patients after spinal injuries. J Physiol (Lond) 1948;107:67-75.

10 Macmillan AL, Spalding JMK. Human sweating response to electrophoresed acetylcholine: a test of postganglionic sympathetic function. $J$ Neurol Neurosurg Psychiatry 1969;32:155-60.

11 Johnson RH. Autonomic failure and the eyes. In Bannister R, ed. Autonomic Failure. Oxford: University Press, 1983:508-42.

12 Appenzeller O, Schnieden H. Neurogenic pathways concerned in reflex vasodilatation in the hand with specia reference to stimulation affecting the afferent pathway. Clin Sci 1963;15:533-40.

13 Johnson RH, Spalding JMK. The effect of surface and central temperature on hand blood flow in subjects with complete transection of the spinal cord. $J$ Physiol (Lond) 1964;170:14-5.

14 Aminoff MJ, Wilcox CS. Autonomic dysfunction in syringomyelia. Postgrad Med J 1972;48:113-5.

15 Nogues MA, Newman PK, Male VJ, Foster JB. Cardiovascular reflexes in syringomyelia. Brain 1982;105 835-49.

16 Hampton F, Williams B, Loizou L. Syncope as a presenting feature of hindbrain herniation with syringomyelia. J Neurol Neurosurg Psychiatry 1982;45 919-22.

17 Tadaki E, Kumazawa T, Mizumura K, Takagi K. Hemihidrosis due to skin pressure with particular remarks $\Omega$ on the intensity and area of the pressure stimuli. Jpn J Physiol 1981;31:259-67.

18 Champion RH, Herxheimer A. Unilateral hyperhidrosis of the trunk. Acta Med Scand 1960;168:17-20.

19 Telford ED. Cervical rib and hyperhidrosis. $\mathrm{Br} \mathrm{Med}$ 응 1942;2:96.

20 Pool JL. Unilateral thoracic hyperhidrosis caused by osteoma of the tenth dorsal vertebra: case report. $J$ Neurosurg 1956;13:111-5.

21 Fewings JD, Hanna MJD, Walsh JA, Whelan RF. The effects of ethyl alcohol on the blood vessels of the hand and forearm in man. $B r J$ Pharmac Chemother 1966;27:93-106.

22 Altura BM, Altura BT. Microvascular and vascular smooth muscle actions of ethanol, acetaldehyde and acetate. Fed Proc 1982;41:2447-51. 